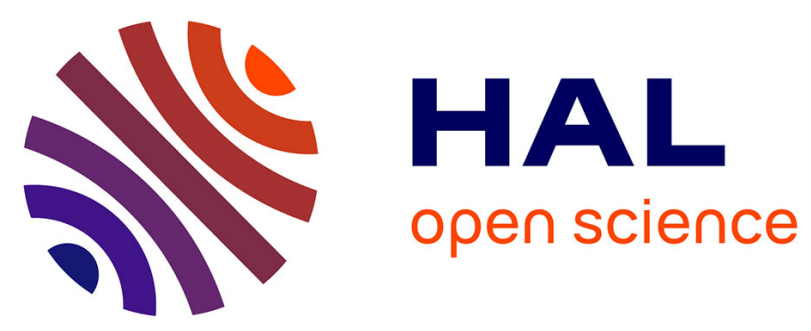

\title{
Safety of vertebral augmentation with cranio-caudal expansion implants in vertebral compression fractures with posterior wall protrusion.
}

Louis Meyblum, Kévin Premat, Mahmoud Elhorany, Eimad Shotar, Évelyne Cormier, Vincent Degos, Hugues Pascal-Mousselard, Sylvie Rosenberg, Frédéric Clarençon, Jacques Chiras

\section{To cite this version:}

Louis Meyblum, Kévin Premat, Mahmoud Elhorany, Eimad Shotar, Évelyne Cormier, et al.. Safety of vertebral augmentation with cranio-caudal expansion implants in vertebral compression fractures with posterior wall protrusion.. European Radiology, In press, 10.1007/s00330-020-06889-4 . hal02880231

\section{HAL Id: hal-02880231 \\ https://hal.sorbonne-universite.fr/hal-02880231}

Submitted on 24 Jun 2020

HAL is a multi-disciplinary open access archive for the deposit and dissemination of scientific research documents, whether they are published or not. The documents may come from teaching and research institutions in France or abroad, or from public or private research centers.
L'archive ouverte pluridisciplinaire HAL, est destinée au dépôt et à la diffusion de documents scientifiques de niveau recherche, publiés ou non, émanant des établissements d'enseignement et de recherche français ou étrangers, des laboratoires publics ou privés. 


\section{Safety of Vertebral Augmentation with Cranio-Caudal Expandable Implants in Vertebral Compression Fractures with Posterior Wall Protrusion}

Louis Meyblum, $\mathrm{MD}^{1}$, Kévin Premat, $\mathrm{MD}^{1}$, Mahmoud Elhorany, $\mathrm{MD}^{1}$, Eimad Shotar, $\mathrm{MD}^{1}$, Évelyne Cormier, $\mathrm{MD}^{1}$, Vincent Degos, $\mathrm{MD}, \mathrm{PhD}^{2}$, Hugues Pascal-Mousselard, MD, $\mathrm{PhD}^{3}$, Sylvie Rosenberg, $\mathrm{MD}^{4}$, Frédéric Clarençon, $\mathrm{MD}, \mathrm{PhD}^{1}$, Jacques Chiras, $\mathrm{MD}^{1}$

1. Sorbonne University, AP-HP, Pitié Salpêtrière - Charles Foix Hospitals, Department of Neuroradiology, F75013, Paris, France

2. Sorbonne University, AP-HP, Pitié Salpêtrière - Charles Foix Hospitals, Department of Anaesthesiology and Critical Care, F75013, Paris, France

3. Sorbonne University, AP-HP, Pitié Salpêtrière - Charles Foix Hospitals, Department of Orthopedic Surgery, F75013, Paris, France

4. Sorbonne University, AP-HP, Pitié Salpêtrière - Charles Foix Hospitals, Department of Rheumatology, F75013, Paris, France 


\section{ABSTRACT}

\section{Objectives}

Vertebral augmentation (VA) has become routinely used in vertebral compression fractures (VCFs). VCFs are often associated with posterior wall protrusion (PWP), which theoretically contraindicates vertebroplasty due to a higher risk of neurological complications. Latest generation of VA devices uses intravertebral cranio-caudal expandable implants to improve the correction of structural deformities but could also be used to prevent further PWP during cement injection. The aim of this study was to evaluate the safety of VA with expandable implant for VCFs with PWP.

\section{Methods}

All consecutive patients treated with expandable implants were considered eligible for inclusion if they met the following criteria: 1) Non-neurological VCF 2) Considered unstable (A3-A4 in AOSpine classification) 3) Significant PWP (>2mm) 4) Back pain with a visual analogue scale (VAS) $\geq 4$. PWPs were independently measured by two investigators; Pearson's statistics were used for interobserver reproducibility.

\section{Results}

Fifty-one consecutive patients, with a mean age of $75 \pm 8.3$ years (range:50-92), were included. There was a slight decrease between mean preoperative $(6.7 \pm 2.2 \mathrm{~mm})$ and postoperative PWP $(6.5 \pm 2.2 \mathrm{~mm})(p=0.02)$, with an excellent interobserver reproducibility (Pearson correlation coefficient $=0.92)$. A mean kyphosis reduction of $34.9 \%( \pm 28.4)$ was observed $(p<0.001) .42$ patients $(82.4 \%)$ had significant pain improvements (mean 
preoperative VAS $=6.9[ \pm 1.7]$ versus $3.1[ \pm 2.0]$ postoperatively $[p<0.001])$. Secondary adjacent level fractures were noted in 16 patients (31.4\%), with a reduction of that risk down to $18.8 \%$ if a preventive adjacent vertebroplasty was performed, without reaching the significance threshold $(p=0.14)$.

\section{Conclusions}

VA with expandable implants appeared safe for non-neurological VCFs with PWP, while allowing satisfactory pain relief. 


\section{KEY POINTS}

1. Vertebral augmentation with cranio-caudal expandable implants is safe for nonneurological vertebral compression fractures with posterior wall protrusion.

2. Vertebral augmentation with cranio-caudal expandable implants might increase the occurrence of secondary adjacent level fractures.

3. Adjacent level vertebroplasty might be helpful to prevent secondary adjacent level fractures.

Keywords: Spinal Fractures; Vertebroplasty; Osteoporotic Fractures; Back Pain 
ABBREVIATIONS AND ACRONYMS

BKP: Balloon Kyphoplasty

CT: Computed Tomography

MRI: Magnetic Resonance Imaging

PMMA: Poly-Methyl-Methacrylate

PVP: Percutaneous Vertebroplasty

PWP: Posterior Wall Protrusion

SALF: Secondary Adjacent Level Fracture

SD: Standard Deviation

VA: Vertebral Augmentation

VAS: Visual Analogue Scale

VCF: Vertebral Compression Fracture

VKA: Vertebral Kyphotic Angle 


\section{INTRODUCTION}

Vertebral Compression Fractures (VCFs) are an important health issue in Western countries, affecting mostly an elderly population [1]. Many adverse events may occur following VCFs, from the consequences of heavy pain medication use to bedsore complications, eventually leading to a twofold higher mortality rate in patients with VCFs [2]. Osteoporotic VCF may also adversely impact the quality of life and represent a considerable economic burden.

Historically, the treatment of VCFs was divided into surgical management with anterior or posterior stabilization and conservative treatment that relied on rest and immobilization.

Although urgent decompression surgery is clearly required in cases of neurological deficits [3], the decision is usually more balanced in non-neurological but symptomatic VCFs [4]. In spite of many controversies [5-9], minimally invasive percutaneous procedures such as percutaneous vertebroplasty (PVP), have arguably found their place and became, among other Vertebral Augmentation (VA) techniques, a first line treatment for non-neurological but symptomatic VCFs, even for elderly patients [10].

During PVP, cement is injected under pressure, which exposes to a double risk of cement leakage and bone fragment protrusion into the spinal canal. Cement leakage results from the propensity of the cement to reach the areas of lower pressure; for instance through a cortical wall rupture or in a venous compartment. Although most of cement leakage are well-tolerated, even when intra-cardiac embolism occurs [11], the risk of neurological compression is the most feared [12]. Thus, Posterior Wall Protrusions (PWPs) are classically considered as contraindication for PVP in most of recent guidelines, including those of the Society of Neurolnterventional Surgery (SNIS) [13] and Cardiovascular and Interventional Radiological Society of Europe (CIRSE) [14]. 
To improve the correction of structural deformities, newer VA techniques have been designed. They basically involve the creation of a cavity inside the vertebral body; either by using the exocentric expansion of a balloon in Balloon Kyphoplasty (BKP), or by deploying an intravertebral implant. Even if BKP allows for such cavity creation; and thereby a lowpressure cement injection; there is an added risk of promoting a posterior wall fragment protrusion due to the balloon expansion [15], which still constitutes an inherent limit and a relative contra-indication to this technique [16].

One of the most recent VA techniques uses an intravertebral cranio-caudal expandable implant called the SpineJack ${ }^{\circledR}$, that is designed to provide sustainable height restoration and kyphosis correction $[17,18]$, which has an efficacy at least comparable with other VA techniques as BKP [19]. Henceforth, these techniques are widely shared among spine specialists and considered first-line options for the treatment of symptomatic VCFs.

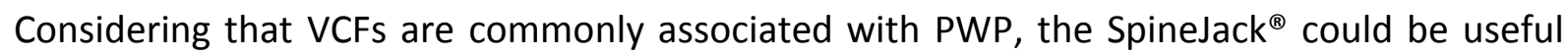
because of its ability to sustainably correct the structural modifications with a likely limited risk of posterior wall fragment mobilization due to the low pressure cement injection. The purpose of this study was to assess the safety of vertebral augmentation with the SpineJack ${ }^{\circledR}$ in VCFs with PWP, by evaluating its impact on PWP measurements before and after the procedure. 


\section{MATERIALS AND METHODS}

The manuscript was prepared according to the STROBE guidelines.

\section{Population}

Data of all consecutive patients who underwent a VA with the SpineJack ${ }^{\circledR}$ for osteoporotic VCFs from January 2012 to January 2019 were retrospectively reviewed. The cohort of patients used for this study includes 7 patients whose data were already analyzed in a previous study about VA with the SpineJack ${ }^{\circledR}$ in chronic vertebral compression fractures with major kyphosis [20].

Patients were considered eligible for inclusion if all following criteria were present: 1) Nonneurological VCF 2) considered unstable (grade A3 or A4 according to AOSpine's classification [21]) 3) Significant PWP (superior to $2 \mathrm{~mm}$ ) 4) Back pain with a visual analogue scale $($ VAS) $\geq 4$

Patients were excluded if any of the following was present: 1) Confirmed malignancy on the pathologic examination of the per-procedural vertebral biopsy 2) Unavailability of preoperative imaging (Computed Tomography [CT] or Magnetic Resonance Imaging [MRI]) on the picture archiving and communication system.

\section{Device}

The only intra-vertebral implant used in this study was the Spinejack ${ }^{\circledR}$ (Stryker, USA). The SpineJack ${ }^{\circledast}$ is an intra-vertebral titanium implant with two end-plates that can be gradually deployed in the cranio-caudal direction. The device exists in 3 dimensions $(4.2 \mathrm{~mm}, 5.0 \mathrm{~mm}$ and $5.8 \mathrm{~mm}$ ) corresponding to the insertion's size of the device, before its deployment, this choice being limited by the pedicle's diameter. 


\section{Procedures}

All interventions were performed under general anaesthesia, bone needles (Thiebaud Biomedical Device, France) were inserted under fluoroscopic X-ray guidance via a bilateral transpedicular approach to the vertebral body. By performing an exchanging manoeuvre over the Kirschner's needle, the working cannulas with the reamer were placed into the vertebral body. After the creation of the central cavity with the template, the SpineJack ${ }^{\circledR}$ implants were inserted and deployed inside the vertebral body until suitable kyphosis reduction and height restoration were reached. Then, the implants were detached. And finally, Poly-Methyl-Methacrylate (PMMA) bone cement (Bone Cement V, Zimmer Biomet, USA) was gently injected under fluoroscopy control until the vertebral body filling was judged satisfactory or interrupted in cases of cement leakages. Adjacent PVP was performed at the operator's discretion, either preventively or for adjacent fractures. A systematic postoperative unenhanced CT-scan was performed directly in the procedure room, in order to find and characterize cement leakages and to control the PWP.

\section{Radiological measures and follow-up}

VCFs were categorized according to the AOSpine's classification [21], and specifically the subgroup of compression fractures with posterior wall involvement ( $\mathrm{3}$ and $\mathrm{A} 4$, respectively incomplete and complete burst fracture). PWP and vertebral kyphotic angle (VKA) were measured on the most recent pre-operative $\mathrm{CT}$ or $\mathrm{MRI}$ and then on the post-operative $\mathrm{CT}$ scan that is systematically performed in our institution.

PWPs were measured on a sagittal plane reconstruction, by drawing a line between the posteroinferior corner of the upper vertebra and the posterosuperior corner of the vertebra 
below. Then, the maximal protrusion of the posterior wall bone fragment was perpendicularly measured rearward from this line (as shown in Figure 1). PWP measures were performed at the same time by two independent assessors (one junior radiologist [L.M], three years of experience; and one senior reviewer [M.E] 10 years of experience, blinded from the first analysis), both blinded on clinical data.

Additional imaging examinations were performed during the follow-up in case of persistent and intractable back pain or in case of pain recurrence and were also reviewed in search of delayed complications. On follow-up imaging, Secondary Adjacent Level Fractures (SALFs) were defined as any new vertebral fracture occurring at a directly adjacent level of treated vertebra(e), in the year following the procedure. When preventive PVPs were performed at an adjacent level, we counted as a SALF any new VCF at the level adjacent to the PVP.

\section{Clinical follow-up}

A systematic clinical examination of each patient was carried out between 4 and 6 weeks after the intervention including pain evaluation using VAS as well as functional improvements. The examination was led by the same operator who performed the VA. Additional consultations were undertaken only in case of persistent pain or occurrence of new symptoms.

Patients lost to follow-up, were kept in the analysis of clinical outcomes. 


\section{Complications}

Periprocedural and delayed complications were systematically assessed and categorized according to the CIRSE classification [22]. Technical complications without clinical impact were classified as grade 1. Minor local hematoma or reversible nerve root compression were classified as grade 2. Hematoma requiring surgery or blood transfusion, life-threatening decompensation of a comorbidity or neurological deficit was classified as grade 3 to 5 depending to the level of sequelae. Procedure related-death was classified as grade 6.

On follow-up imaging, Secondary Adjacent Level Fractures (SALFs) were defined as any new vertebral fracture occurring at a directly adjacent level of treated vertebra(e), in the year following the procedure. When preventive PVPs were performed at an adjacent level, we counted as a SALF any new VCF at the level adjacent to the PVP.

\section{Ethical Statement}

Neither approval of the institutional review board nor patient informed consent was required by the ethics committee of our Institution for retrospective analyses of patients' records and imaging data.

\section{Statistical analysis}

All analysis was performed using the open source software R (version 3.5.2).

Comparisons of means were performed using a Student-t test or, if the Shapiro-Wilk test rejected the normality of the studied variables' distribution, with a Wilcoxon test. The $\chi^{2}$ test 
was used for comparisons of proportions. Results were considered statistically significant when $p$-values were inferior to 0.05 .

Inter-observer reproducibility was evaluated using the Pearson correlation coefficient, interpreted as follows: poor $(<0.20)$, fair $(0.21-0.40)$, satisfactory $(0.41-0.60)$, good $(0.61-$ $0.80)$, and excellent (0.81-1.00). 


\section{RESULTS}

One hundred twenty-eight patients underwent VA with the SpineJack ${ }^{\circledast}$ during the study period and were screened. Finally, 51 patients (40 females, 11 males), with an average age of $75 \pm 8.3$ years (range: $50-92$ ) were kept for the analysis (Figure 2). Forty-eight fractures (94.1\%) were caused by minor trauma with underlying osteoporotic condition and 3 fractures (5.9\%) were caused by high kinetic trauma. Baseline characteristics of the patients are shown in Table 1.

Six patients (11.8\%) were lost to the clinical follow-up, but radiological measurements were available for every patient. VA with the SpineJack ${ }^{\circledR}$ was performed at one level in each case and the most frequently affected vertebra was $L 1(n=23,45.1 \%)$. In 32 cases $(62.7 \%)$ a simultaneous complementary PVP was performed and in half of those cases $(31.4 \%)$ for preventive purposes.

Mean preoperative PWP was $6.7 \mathrm{~mm}( \pm 2.2$; range: $2.5-13.0)$ and mean postoperative

PWP was $6.5 \mathrm{~mm}( \pm 2.2$; range: $3.0-13.0$ ). Comparison between pre and post-operative PWP showed a slight reduction of the PWP $(p=0.02)$, even if clinically negligible. There was an excellent interobserver reproducibility with a correlation coefficient of 0.92 . Mean VKA was $-17.5^{\circ}( \pm 7.9)$ pre-operatively and decreased to $-11.1^{\circ}( \pm 6.9)$ post-operatively $(p<$ 0.001 ), averaging $34.9 \%$ ( \pm 28.4 ) of kyphosis reduction. Forty-two patients $(82.4 \%)$ had pain improvements with a mean VAS decreasing from $6.9( \pm 1.7)$ preoperatively to $3.1( \pm 2.0)$ postoperatively $(p<0.001)$. Among 31 patients with significant walking disorders before the procedure, 12 showed a complete regression of these troubles $(38.7 \%), 10$ incomplete 
resolution (32.3\%), 5 patients experienced no functional improvements (16.1\%) and 4 were lost to follow-up (12.9\%).

Cement leakages occurred in 21 cases (41.2\%) and were intra-discal in 12 cases (23.5\%). Other cement leakages mostly affected the venous system: epidural vein in 4 cases $(7.8 \%)$, para-vertebral vein in 3 cases (5.9\%) and foraminal vein in 1 case (2.0\%). In only 1 case (2.0\%), a posterior cement leakage inside the fracture site was observed (Figure 3). All of them were asymptomatic. One patient $(2.0 \%)$ presented a minor cement pulmonary embolism that remained asymptomatic. Procedure-related complications are summarized in

\section{Table 2.}

In the year following SpineJack ${ }^{\circledR}$ implantation, 21 SALFs occurred in 17 patients (33.3\%). The rate of SALF seemed lower in the group with preventive adjacent PVP (18.8\%) versus $40.0 \%$ when no preventive PVP were performed, without reaching the significance threshold $(p=0.14)$. Of note, no SALF occurred at a level adjacent to a discal cement leakage. In subgroup analysis, SALFs were significantly more likely to occur when a complete burst fracture (grade A4) was present $(p<0.05)$. Subgroup analysis of SALFs is shown in Table 3. 


\section{DISCUSSION}

This study is the one of the first to focus on VA with latest generation devices, such as the SpineJack ${ }^{\circledR}$, in VCFs with PWP. The results of this work suggested that this technique is safe in this indication; allowing slight improvement of the posterior wall bulging, thus preventing neurological complications. We also confirmed its effectiveness, by providing satisfactory pain relief, substantial improvements of walking disability and significant kyphosis correction.

PVP is classically considered contraindicated in VCFs with PWP, as both the risks of displacement of the posterior wall fragment and cement leakage due to the posterior wall injury may lead to neurological complications [12]. BKP may also seem dangerous when a PWP is present considering that this technique requires balloon inflation for the expansion of the vertebra that could also promote bone fragment mobilization. Thus, VA with the Spinejack ${ }^{\circledR}$ appeared to be a valuable alternative, as the expansion force is only applied in the cranio-caudal direction, which could limit an unintended thrust force against the posterior wall and its potential consequences. Furthermore, the cavity creation allow a lowpressure cement injection and thus reducing the risk of leakage, that can explain the rate of cement leakage found in our study, which is comparable to other studies of VA for burst fracture [23].

Another limitation of BKP is the lack of sufficient vertebral height restoration or pathological angulation correction. Indeed, some studies, such as the Kaviar Trial, found that the improvement of the kyphosis was weak and similar to those of the PVP [24]. It is possible that height restoration and kyphosis correction cannot be sustained after the deflation of the balloon prior to cement injection [25]. In this indication, VA with SpineJack ${ }^{\circledR}$ seems more 
effective with better results on height restoration and kyphosis correction [26, 27], considering that the implant may help to hold the thrust force and provide a more sustainable expansion [17], either in acute or in chronic vertebral fracture [20].

This study seemed to show that VA with the Spinejack ${ }^{\circledR}$ was efficiently able to prevent further PWP. The same observations were made by a recently published study by Venier et al [28], which also explored the impact of VA technique on PWP, finding a significant reduction of postoperative PWP that they explained by the ligamentotaxis effect of the posterior longitudinal ligament. Besides undeniable resemblances with our work, one asset of our cohort is its homogeneity, with the use of a single kind of implant, without any surgical stabilization associated to VA. Both studies adds to the body of literature that PWPs without neurological deficits may not be any more considered as absolute contraindications to reinforced VA techniques such as the SpineJack ${ }^{\circledR}$ or other armed cementoplasty techniques.

The other subject disclosed by this study is the high rate SALFs (31.4\%) recorded during the follow-up, that seemed higher than the risk of SALF after PVP (estimated at $13.7 \%$ in a recent meta-analysis [29]). SALFs are allegedly consecutive to the altered biomechanical properties induced by cementation, which increases the stiffness of the treated vertebra and reports unusual constraints to the adjacent levels [30]. One of the weaknesses in our study is the absence of control group, which do not allow to eliminate the effect of possible confounding factors on these finding, as could be the severity of osteoporosis.

The risk of secondary fractures after VA procedures has been scantly studied. Possibly, the important modifications of local constraints due to the cranio-caudal expansion of the device could explain an increase of that risk. We also noted that complete burst fractures were 
significantly associated with the onset of SALFs, which may be explained by both an increase of the load transfer to the adjacent vertebra or by the fact that burst fractures may reflect profound osteopenia. PVP was regularly employed along this study to prevent such complications, particularly in case of severe osteoporosis. This technique, already performed for the prevention of new fracture after PVP [31], should be even more interesting in VA with the SpineJack ${ }^{\circledast}$ due to a potential higher risk of SALF. Even if our results suggested a possible effectiveness of this preventive PVP, the low number of patients and the design of this study do not permit to definitively confirm it. Another potential solution to reduce the rate of SALF could be the use of silicone elastomeric material instead of PMMA cement [32], but needs to be weighed against a potentially higher risk of cement leakage and pulmonary embolism [33].

Targeted studies exploring this specific topic are awaited and could help elucidate the implication of the VA with the SpineJack ${ }^{\circledR}$ in these SALFs. Nevertheless, the high rate of SALF suggested that operators should be particularly careful during the follow-up of these patients. Furthermore, optimal medical management of osteoporosis remains critical, as anti-osteoporotic medications have been shown to reduce the risk of subsequent vertebral fractures by 40 to $70 \%[34]$.

This study entails several limitations. Firstly, the monocentric and retrospective nature of data collection is source of multiple biases. Moreover, the low number of patients included and the scarcity of neurological complications after percutaneous procedures may explain these results of our study. The primary endpoint, based on a radiological measure, was evaluated by two non-blinded investigators, with the aim to reduce the impact linked to potential measurement bias. The clinical endpoints, even more subjective, may have been 
influenced by the non-controlled non-blinded evaluation of the results by the operator during the follow-up.

Nevertheless, this study is one of the largest cohorts to date to emphasize the SpineJack ${ }^{\circledR}$ technique in this subset of patients and suggested that VA with the SpineJack ${ }^{\circledR}$ for VCFs with PWP is a safe procedure that prevents neurological complications while providing satisfactory pain relief and functional improvements.

However, all the advantages that could be expected from the SpineJack ${ }^{\circledR}$, either in terms of effectiveness (analgesia, functional improvements and structural deformities' correction) or safety needs to be confirmed in a larger population. 


\section{REFERENCES}

1. Schousboe JT (2016) Epidemiology of Vertebral Fractures. Journal of Clinical Densitometry 19:8-22. https://doi.org/10.1016/j.jocd.2015.08.004

2. Lau E, Ong K, Kurtz S, et al (2008) Mortality Following the Diagnosis of a Vertebral Compression Fracture in the Medicare Population: The Journal of Bone and Joint Surgery-American Volume 90:1479-1486. https://doi.org/10.2106/JBJS.G.00675

3. Benzel EC, Larson SJ (1986) Functional Recovery after Decompressive Operation for Thoracic and Lumbar Spine Fractures: Neurosurgery 19:772-778. https://doi.org/10.1227/00006123-198611000-00009

4. Wood KB, Buttermann GR, Phukan R, et al (2014) Operative Compared with Nonoperative Treatment of a Thoracolumbar Burst Fracture without Neurological Deficit: A Prospective Randomized Study with Follow-up at Sixteen to Twenty-Two Years*. The Journal of Bone and Joint Surgery-American Volume 97:3-9. https://doi.org/10.2106/JBJS.N.00226

5. Kallmes DF, Comstock BA, Heagerty PJ, et al (2009) A Randomized Trial of Vertebroplasty for Osteoporotic Spinal Fractures. New England Journal of Medicine 361:569-579. https://doi.org/10.1056/NEJMoa0900563

6. Buchbinder R, Mitchell P, Med M, et al (2009) A Randomized Trial of Vertebroplasty for Painful Osteoporotic Vertebral Fractures. New England Journal of Medicine 361:557568. https://doi.org/10.1056/NEJMoa0900429

7. Clark W, Bird P, Gonski P, et al (2016) Safety and efficacy of vertebroplasty for acute painful osteoporotic fractures (VAPOUR): a multicentre, randomised, double-blind, placebo-controlled trial. The Lancet 388:1408-1416. https://doi.org/10.1016/S01406736(16)31341-1

8. Buchbinder R, Johnston RV, Rischin KJ, et al (2018) Percutaneous vertebroplasty for osteoporotic vertebral compression fracture. Cochrane Database of Systematic Reviews. https://doi.org/10.1002/14651858.CD006349.pub3

9. Firanescu CE, de Vries J, Lodder P, et al (2018) Vertebroplasty versus sham procedure for painful acute osteoporotic vertebral compression fractures (VERTOS IV): randomised sham controlled clinical trial. BMJ k1551. https://doi.org/10.1136/bmj.k1551

10. Clarençon F, Fahed R, Gabrieli J, et al (2016) Safety and Clinical Effectiveness of Percutaneous Vertebroplasty in the Elderly ( $\geq 80$ years). European Radiology 26:23522358. https://doi.org/10.1007/s00330-015-4035-2

11. Fadili Hassani S, Cormier E, Shotar E, et al (2019) Intracardiac cement embolism during percutaneous vertebroplasty: incidence, risk factors and clinical management. Eur Radiol 29:663-673. https://doi.org/10.1007/s00330-018-5647-0 
12. Cosar M, Sasani M, Oktenoglu T, et al (2009) The major complications of transpedicular vertebroplasty. Journal of Neurosurgery: Spine 11:607-613.

https://doi.org/10.3171/2009.4.SPINE08466

13. Chandra RV, Meyers PM, Hirsch JA, et al (2014) Vertebral augmentation: report of the Standards and Guidelines Committee of the Society of Neurolnterventional Surgery. J Neurolntervent Surg 6:7-15. https://doi.org/10.1136/neurintsurg-2013-011012

14. Tsoumakidou G, Too CW, Koch G, et al (2017) CIRSE Guidelines on Percutaneous Vertebral Augmentation. Cardiovasc Intervent Radiol 40:331-342. https://doi.org/10.1007/s00270-017-1574-8

15. Saliou G, Rutgers DR, Kocheida EM, et al (2010) Balloon-Related Complications and Technical Failures in Kyphoplasty for Vertebral Fractures. AJNR Am J Neuroradiol 31:175-179. https://doi.org/10.3174/ajnr.A1783

16. Masala S, Fiori R, Massari F, Simonetti G (2005) Kyphoplasty: indications, contraindications and technique. Radiol Med 110:97-105

17. Noriega DC, Rodriguez-Monsalve F, Ramajo R, et al (2018) Long-term safety and clinical performance of kyphoplasty and SpineJack ${ }^{\circledR}$ procedures in the treatment of osteoporotic vertebral compression fractures: a pilot, monocentric, investigatorinitiated study. Osteoporosis International. https://doi.org/10.1007/s00198-018-4773-5

18. Kerschbaumer G, Gaulin B, Ruatti S, et al (2019) Clinical and radiological outcomes in thoracolumbar fractures using the SpineJack device. A prospective study of seventyfour patients with a two point three year mean of follow-up. International Orthopaedics (SICOT) 43:2773-2779. https://doi.org/10.1007/s00264-019-04391-1

19. Noriega D, Marcia S, Theumann N, et al (2019) A prospective, international, randomized, noninferiority study comparing an implantable titanium vertebral augmentation device versus balloon kyphoplasty in the reduction of vertebral compression fractures (SAKOS study). The Spine Journal 19:1782-1795. https://doi.org/10.1016/j.spinee.2019.07.009

20. Premat K, Vande Perre S, Cormier É, et al (2018) Vertebral augmentation with the SpineJack ${ }^{\circledR}$ in chronic vertebral compression fractures with major kyphosis. European Radiology 28:4985-4991. https://doi.org/10.1007/s00330-018-5544-6

21. Schnake KJ, Schroeder GD, Vaccaro AR, Oner C (2017) AOSpine Classification Systems (Subaxial, Thoracolumbar): Journal of Orthopaedic Trauma 31:S14-S23. https://doi.org/10.1097/BOT.0000000000000947

22. Filippiadis DK, Binkert C, Pellerin O, et al (2017) Cirse Quality Assurance Document and Standards for Classification of Complications: The Cirse Classification System. Cardiovasc Intervent Radiol 40:1141-1146. https://doi.org/10.1007/s00270-017-1703-4 
23. Lee IJ, Choi AL, Yie M-Y, et al (2010) CT evaluation of local leakage of bone cement after percutaneous kyphoplasty and vertebroplasty. Acta Radiologica 51:649-654. https://doi.org/10.3109/02841851003620366

24. Dohm M, Black CM, Dacre A, et al (2014) A randomized trial comparing balloon kyphoplasty and vertebroplasty for vertebral compression fractures due to osteoporosis. AJNR Am J Neuroradiol 35:2227-2236.

https://doi.org/10.3174/ajnr.A4127

25. Verlaan J-J, van de Kraats EB, Oner FC, et al (2005) The reduction of endplate fractures during balloon vertebroplasty: a detailed radiological analysis of the treatment of burst fractures using pedicle screws, balloon vertebroplasty, and calcium phosphate cement. Spine 30:1840-1845. https://doi.org/10.1097/01.brs.0000173895.19334.e2

26. Krüger A, Oberkircher L, Figiel J, et al (2015) Height restoration of osteoporotic vertebral compression fractures using different intravertebral reduction devices: a cadaveric study. The Spine Journal 15:1092-1098.

https://doi.org/10.1016/j.spinee.2013.06.094

27. Lin J-H, Wang S-H, Lin E-Y, Chiang Y-H (2016) Better Height Restoration, Greater Kyphosis Correction, and Fewer Refractures of Cemented Vertebrae by Using an Intravertebral Reduction Device: a 1-Year Follow-up Study. World Neurosurgery 90:391-396. https://doi.org/10.1016/j.wneu.2016.03.009

28. Venier A, Roccatagliata L, Isalberti M, et al (2019) Armed Kyphoplasty: An Indirect Central Canal Decompression Technique in Burst Fractures. AJNR Am J Neuroradiol ajnr;ajnr.A6285v1. https://doi.org/10.3174/ajnr.A6285

29. Han SL, Wan SL, Li QT, et al (2015) Is vertebroplasty a risk factor for subsequent vertebral fracture, meta-analysis of published evidence? Osteoporos Int 26:113-122. https://doi.org/10.1007/s00198-014-2848-5

30. Baroud G, Heini P, Nemes J, et al (2003) Biomechanical Explanation of Adjacent Fractures Following Vertebroplasty [letter]. Radiology 229:606-608. https://doi.org/10.1148/radiol.2292030378

31. Yen $\mathrm{CH}$, Teng $\mathrm{MMH}$, Yuan $\mathrm{WH}$, et al (2012) Preventive Vertebroplasty for Adjacent Vertebral Bodies: A Good Solution to Reduce Adjacent Vertebral Fracture after Percutaneous Vertebroplasty. AJNR Am J Neuroradiol 33:826-832. https://doi.org/10.3174/ajnr.A2898

32. Mauri G, Nicosia L, Sconfienza LM, et al (2018) Safety and results of image-guided vertebroplasty with elastomeric polymer material (elastoplasty). Eur Radiol Exp 2:31. https://doi.org/10.1186/s41747-018-0062-5

33. Urlings TAJ, van der Linden E (2013) Elastoplasty: First Experience in 12 Patients. Cardiovasc Intervent Radiol 36:479-483. https://doi.org/10.1007/s00270-012-0409-x 
34. Ebeling PR, Akesson K, Bauer DC, et al (2019) The Efficacy and Safety of Vertebral Augmentation: A Second ASBMR Task Force Report. J Bone Miner Res 34:3-21. https://doi.org/10.1002/jbmr.3653 


\section{FIGURES AND TABLES}

\section{Figure 1.}

Seventy-year-old patient with past history of osteoporosis presenting a painful L1 vertebral compression fracture, graded A4 according to the AOSpine classification, without any neurological deficit. (A) Preoperative CT, sagittal reconstructions, vertebral kyphotic angle (VKA) and posterior wall protrusion (PWP) $(8.0 \mathrm{~mm})$. (B) Peroperative plain X-ray, lateral projection, showing adequate deployment of both implants. (C) Post-procedure control plain X-ray displaying optimal filling of the vertebral body. (D) Postoperative CT, sagittal reconstruction: Restoration of vertebral height and correction of local kyphosis without increasing the PWP $(7.5 \mathrm{~mm})$.
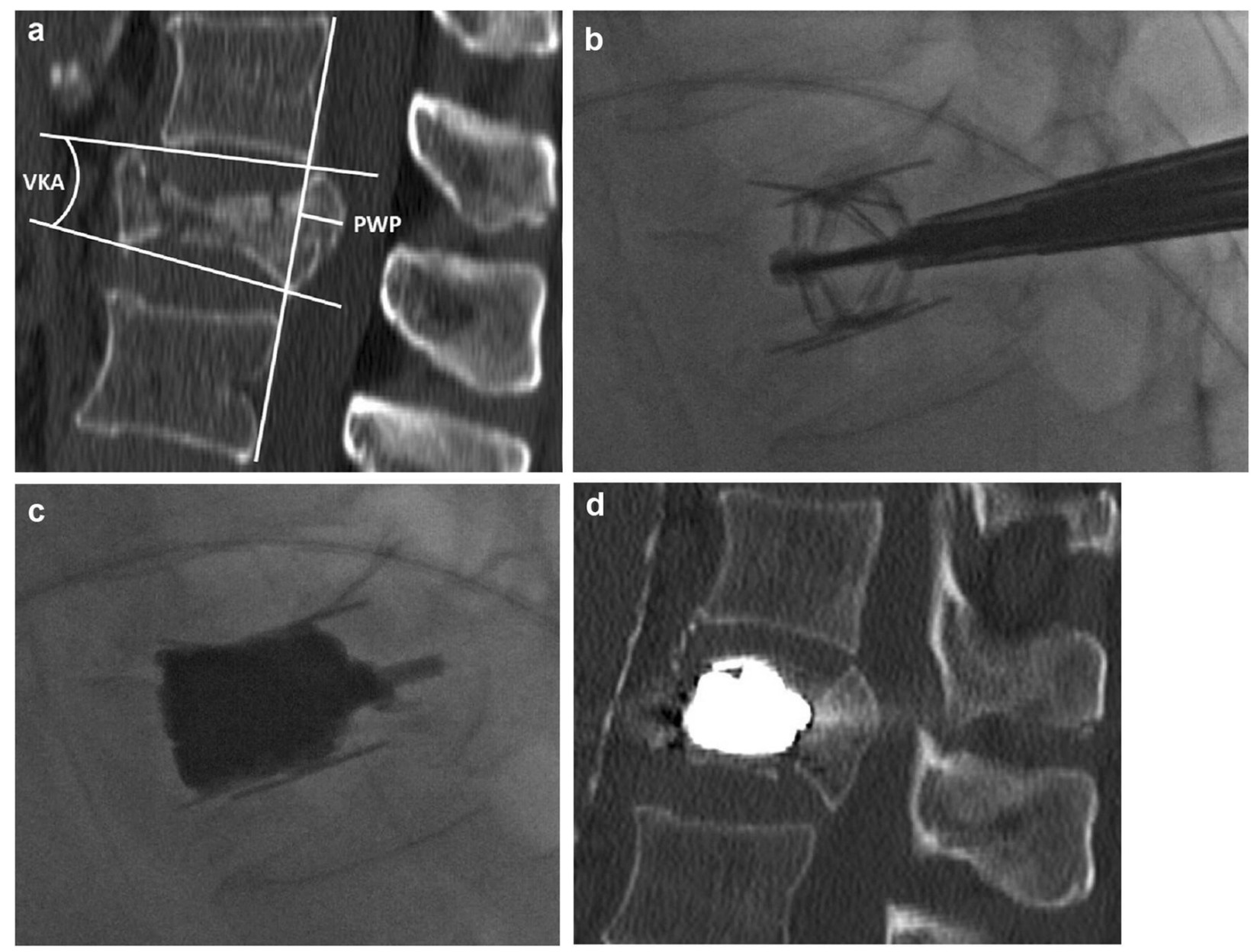


\section{Figure 2.}

Study Flowchart.

PWP: Posterior Wall Protrusion; CT: Computed Tomography; MRI: Magnetic Resonance Imaging

Patients assessed for eligibility ( $n=128)$

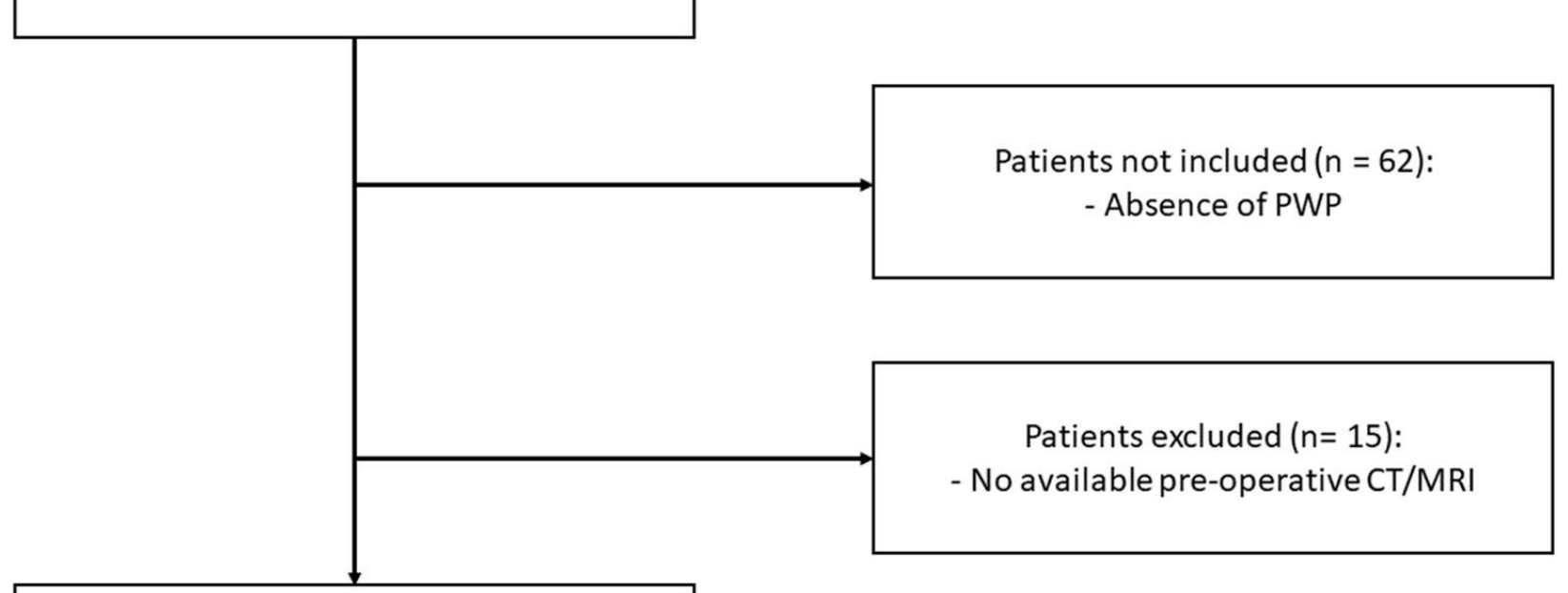

Patients finally included in the analysis $(n=51)$ 


\section{Figure 3.}

Seventy-year-old patient with osteoporosis presenting a symptomatic T12 VCF, classified A4, with a complete involvment of the posterior wall and osteonecrosis (A). Preventive PVPs were performed at the adjacent levels. (B) Control CT scan, axial slice on T12 showing posterior cement leakage restrained inside the fracture site without any majoration of canal narrowing. (C, D) Preoperative and postoperative MRIs showing no modification of the PWP. The patient was discharged symptoms-free at day 1.
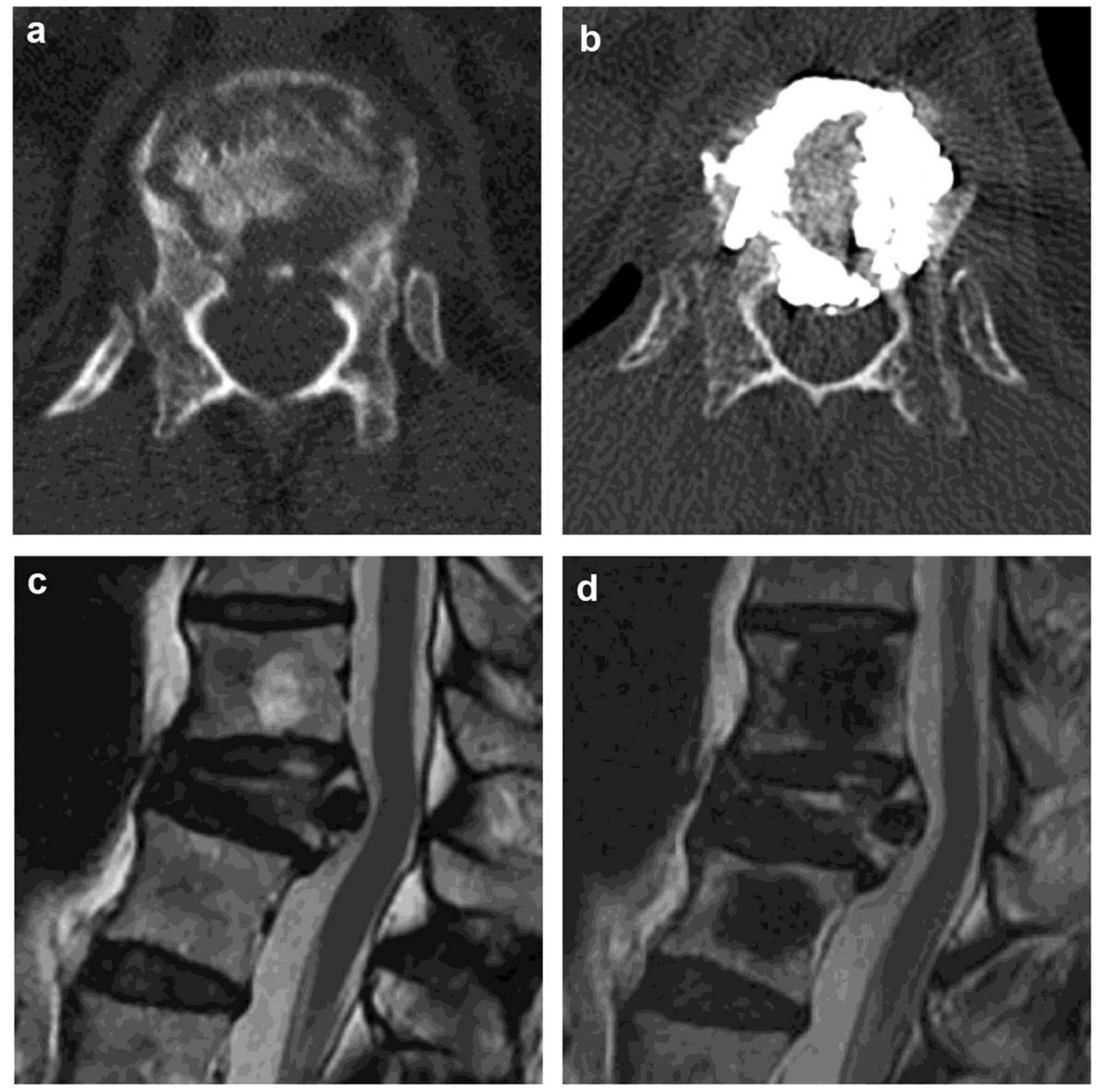
Table 1. Patients' baseline characteristics

${ }^{1}$ According to the AOSpine classification.

\begin{tabular}{|l|c|}
\hline Characteristic & $\mathbf{n}(\%)$ \\
\hline Sex & 40 Females (78.4\%), 11 Males (21.6\%) \\
\hline Age & $75(50-92)$ \\
\hline Treated level & \\
- T12 & $19(37.3 \%)$ \\
- L1 & $23(45.1 \%)$ \\
- L2 & $6(11.8 \%)$ \\
- L3 & $2(3.9 \%)$ \\
- L4 & $1(2.0 \%)$ \\
\hline Type of fracture & \\
- A3 & $12(23.5 \%)$ \\
- A4 & $39(76.5 \%)$ \\
\hline Type of traumatism & \\
- Minor traumatism & $48(94.1 \%)$ \\
- High kinetic traumatism & $3(5.9 \%)$ \\
\hline Type of SpineJack & \\
- 4.2mm & $16(31.4 \%)$ \\
- 5.0mm & $34(66.7 \%)$ \\
\hline Associated vertebroplasty & $17(33.3 \%)$ \\
\hline Adjacent level vertebroplasty & $32(62.7 \%)$ \\
\hline & \\
\hline & \\
\hline & \\
\hline
\end{tabular}


Table 2. Procedure-related complications

SALF: Secondary Adjacent Level Fractures ; S.D : Standard Deviation

\begin{tabular}{|l|c|}
\hline Characteristic & $\mathbf{n}(\%)$ \\
\hline Patients with SALFs & $17(33.3 \%)$ \\
\hline Number of SALFs & $21(41.2 \%)$ \\
\hline Cement leakage: & $21(41.2 \%)$ \\
- Foraminal & $1(2.0 \%)$ \\
- Para-vertebral & $3(5.9 \%)$ \\
- Epidural & $5(9.8 \%)$ \\
- Intra-discal & $13(25.5 \%)$ \\
\hline Cement volume injected & $5.7( \pm 1.2)$ \\
(士S.D) & \\
\hline
\end{tabular}


Table 3. Exploratory analysis of secondary adjacent level fractures

S.D: Standard Deviation

\begin{tabular}{|c|c|c|c|}
\hline Parameter & $\begin{array}{l}\text { Patients with } \\
\text { SALF } \\
\quad(n=17)\end{array}$ & $\begin{array}{c}\text { Patients } \\
\text { without SALF } \\
\quad(n=34)\end{array}$ & P-value \\
\hline Mean age ( \pm S.D) & $78( \pm 8.4)$ & $74( \pm 8.0)$ & 0.14 \\
\hline Intradiscal leaks (n; \%) & $3(17.6 \%)$ & $9(26.5 \%)$ & 0.48 \\
\hline $\begin{array}{l}\text { Mean cement volume (mL } \\
\pm \text { S.D) }\end{array}$ & $5.7( \pm 1.4)$ & $5.8( \pm 1.1)$ & 0.85 \\
\hline Complete burst fracture & $17(100.0 \%)$ & $22(64.7 \%)$ & $<0.05$ \\
\hline $\begin{array}{l}\text { Preventive adjacent } \\
\text { vertebroplasty }\end{array}$ & $3(17.6 \%)$ & $13(38.2 \%)$ & 0.14 \\
\hline $\begin{array}{l}\text { Mean vertebral kyphotic } \\
\text { angle correction (\%; } \pm \text { S.D) }\end{array}$ & $32.4 \%( \pm 26.5)$ & $34.1 \%( \pm 27.8)$ & 0.68 \\
\hline
\end{tabular}

